\title{
Effect of Gum Arabic as Dietary Supplement for Type II Diabetes in Jabir Abu Aliz Diabetic Center- (Khartoum State)
}

\author{
Niama Mirghani Ibrahim ${ }^{1}$, Almahdi Mohammed $\mathrm{Ali}^{2}$, Nadia Abdel Rahim Khogali ${ }^{3}$ \& Hiba Shawgi Bashir ${ }^{4}$ \\ ${ }^{1}$ Department of Basic Sciences, Faculty of Nursing Sciences, University of Khartoum, Khartoum, Sudan \\ ${ }^{2}$ Department of Medicine, Faculty of Medicine, University of Khartoum, Khartoum, Sudan \\ ${ }^{3}$ Department of Nutrition and Dietetics, Faculty of Education, University of Khartoum, Khartoum, Sudan \\ ${ }^{4}$ Khartoum state, Sudan \\ Correspondence: Niama Mirghani Ibrahim, Faculty of Nursing Sciences, University of Khartoum, Khartoum, \\ Sudan. Tel: 24-912-300-238.
}

\author{
Received: January 6, 2017 Accepted: April 23, 2017 Online Published: May 8, 2017 \\ doi:10.5539/gjhs.v9n7p168 URL: https://doi.org/10.5539/gjhs.v9n7p168
}

\begin{abstract}
Background: Gum Arabic (Acacia Senegal) is a water-soluble dietary fiber considered to be safe by the United States Food and Drug Administration since the 1970s.Recent studies showed the therapeutic action of Gum Arabic.

Methods: It was Quasi-experimental study design. The objective of this study was to determine the effects of regular Gum Arabic ingestion as dietary supplement on accumulative blood glucose $\left(\mathrm{HbA}_{1 c}\right)$ and body mass index (BMI) among type II diabetes in Jabir Abu Aliz Diabetic Center in Khartoum. 49 type II diabetes were provided with Gum Arabic at the beginning of the trial and educated to add $60 \mathrm{~g} /$ day (divided into two portions $30 \mathrm{gm}$ ) to their meals for three months. Food consumption, BMI, and HbA1C were assessed for all the patients before and after the consumption of Gum Arabic for three months. Data was processed using SPSS version (20) and paired ttest was used to determine the effect of Gum Arabic on studied parameters.
\end{abstract}

Results: It showed that regular intake of $60 \mathrm{~g} /$ day of Gum Arabic for three months showed slight reduction in BMI for diabetes (no significant difference), and slight change in $\mathrm{HbA}_{1 \mathrm{c}}$ (no significant difference). This may be due to the fact that majority of the respondents (60\%) increased their carbohydrates intake in their daily meals because of winter, also respondents did not abide fully () to consumption of Gum Arabic, where only (32\%) of the patients were fully committed to the consumption of Gum Arabic.

Keywords: diabetic patients, dietary fibers, Gum Arabic

\section{Introduction}

Non-insulin dependent diabetes mellitus (NIDDM) known as type II diabetes is one of the most common chronic diseases in the world. Approximately $90 \%$ of diabetes diagnosed as having diabetes has type II, and an additional 4-5 million people meet the diagnostic criteria, but have not yet been diagnosed (Haslett et al., 2002; Eliadarous, 2007; Kumar \& Clark, 1998).

Socioeconomic status and urban or rural habitation may influence incidence rates. The most important risk factors for development of NIDDM are increasing age, heredity, and obesity (Davidson, 1998; Bays et al., 2007; Sizer \& Whitney, 2008). Glycosylated hemoglobin $\left(\mathrm{HbA}_{1}\right.$, or $\mathrm{HbA}_{1 \mathrm{c}}$ ) was introduced into clinical practice nearly 15 years ago as an index of long-term diabetic control and now are widely utilized. This test provides an index of the average blood glucose concentration (two to three months). Diabetes should maintain the ratio of HbA1c to less than $(7 \%)$.

Dietary Fiber has long been known to promote good digestive health and regulatory functions, but those are only two of the many benefits fiber offers. In addition high-fiber diet reduces cholesterol levels, the risk of heart disease, diabetes, and keeps the body weight in check (Mohamed et al., 2015; Anonymous, 2008; Nasir et al., 2012)

Gum Arabic can be used as dietary supplement for diabetes, because some studies showed that it is important in treatment of many diseases like obesity, colon cancer, kidney diseases, hyperlipidemia, and diabetes (Calame et al., 2011; Glover et al., 2009; Karg et al., 2000; Nasir et al., 2008 ;Chiavaroli et al., 2014; Alsuleimani et al., 2015). 
Gum Arabic is able to decrease the caloric intake and increase feeling satiated. It could be used in a dietary approach to control body weight development (Calame et al., 2011).

In fact, Gum Arabic is safe for most adults. It may cause gas bloating and loose stools. Some people may be allergic to Gum Arabic particularly skin reaction. It is not advisable to use Gum Arabic during pregnancy and breast-feeding (Anonymous, 2012).

\subsection{Hypotheses}

\subsubsection{Null Hypothesis (H0)}

- Consumption of Arabic gum has no beneficial effect on blood glucose of type II diabetes.

- Consumption of Arabic gum has no effect on body weight of type II diabetes.

1.1.2 Alternative Hypothesis (HA)

- Consumption of Arabic gum has a beneficial effect on blood glucose for type II diabetes

- Consumption of Arabic gum has an effect on body weight of type II diabetes.

\subsection{Problem Statement}

Diabetes is a chronic and incurable disease develops when the body is not producing enough or effective insulin. As a result the glucose remains in the blood and the person's blood sugar levels become too high. This can result in being potentially dangerous, even deadly if left untreated for an extended period of time.

This research may help improving the health and nutrition status of diabetes by using Gum Arabic as dietary supplement for them. This should be very useful for diabetes in Sudan, where Gum Arabic is grown in many parts of the country, and can easily be found at local groceries for a reasonable price (Osman et al., 2011).

\subsection{Research Objectives}

\subsubsection{General Objective}

To investigate the potential of using Gum Arabic as dietary supplement for NIDDM diabetes.

\subsubsection{Specific Objectives}

1). To determine the effect of the addition of Gum Arabic on accumulative blood glucose $\left(\mathrm{HbA}_{1 \mathrm{c}}\right)$ of type II diabetes.

2). To assess the effect of Gum Arabic on body weight and Body Index.

\section{Subjects, Materials and Methods}

\subsection{Study Design}

It was pre and post quantitative experimental quasi study which designed to conform to the medical literature, reducing confounders and eliminating the need for a control group.

\subsection{Study Area}

This study was conducted in Jabir Abu Aliz Diabetic Centre (JADC) in Khartoum city. JADC was inaugurated in 1998 by the Khartoum State Ministry of Health as the first multidisciplinary specialized diabetes center in the Sudan. It caters for 40, 000 registered diabetes with a monthly turnover of 450 new patients per month and 200 outpatients per day.

\subsection{Study Population}

\subsubsection{Inclusion Criteria}

- Diabetes with Type II Diabetes mellitus (Non-Insulin Dependent Diabetes Mellitus) from Jabir Abu Aliz Diabetic center in Khartoum city.

- Male and female patients who agree to participate were included.

\subsubsection{Exclusion Criteria}

Pregnant women, children, and those who disagree to participate.

\subsubsection{Sample Size Calculation}

To satisfy the objectives of the study. Sample size $(n)$ is calculated using the following formula: 


$$
\begin{gathered}
n=\frac{2\left(Z_{1-\frac{\alpha}{2}} Z_{1-\beta}\right)^{2}}{\Delta^{2}}+\frac{Z_{1-\alpha / 2}^{2}}{2} \\
\Delta=\frac{\delta}{\sigma}
\end{gathered}
$$

$\Delta$ is the (standardized effect size)

$\delta$ is the difference between two means

$\sigma$ is the standard deviation

$Z_{1-\beta}$ is the value from the normal distribution related to and representing the power of the test.

$Z_{\alpha}$ is the value from the normal distribution related to and representing the confidence level.

$n$ is the population Size

$Z_{1-\beta / 2}$ Equal to 1.96 for $95 \%$ confidence level.

$\mathrm{Z}_{1-\beta}$ equal to 0.8416 for $80 \%$ power from the results of pre-test:

$$
\Delta=\frac{18.8}{44.8}
$$

Thus $\Delta=0.45$

Accordingly

$$
n=\frac{2(1.96 \times 0.8416)^{2}}{(0.45)^{2}}+\frac{(1.96)^{2}}{2}=29 \text { patients }
$$

49 patients were chosen, because of attrition.

\subsubsection{Sampling Techniques}

Sample of this research was selected by case-finding procedure. Patients were provided with Hashab Gum supplements (Acacia Senegal), which produces in Kordofan State to take it as dietary supplement on daily basis for three months. This Gum Arabic produced by Elanan Trading Exports and Imports Company Ltd., Khartoum, Sudan.

The objectives of this research were clearly explained to the patients who agreed to participate in the research. The Gum Arabic supplement was limited to $60 \mathrm{gm} /$ day as recommended by (Chandalia et al. 2000). This amount of Gum Arabic was divided into two portions $(30 \mathrm{gm})$ twice or three times a day and it was incorporated with food as recommended by (Ushida et al. 2011).The patients were advised to increase their water intake and they were regularly monitored by the health center. Also they were followed by telephone.

\subsection{Data Collection}

Data collection was carried by using questionnaire which divided into six parts .The first part contains general information (name, age, sex, residence, religion, address, mobile number, medical history and type of treatment).The second part represent social and economic information (educational level, income level and job).The third part represents nutritional information (the number of daily meals and special meals).The fourth part contains anthropometric measurements (weight and height). The fifth part includes lab tests (blood Sugar Level).

\subsubsection{Anthropometric Measurements}

- Weight $(\mathrm{kg})$ and height $(\mathrm{cm})$ were measured by using height and weight measuring machine type of (seca), made in Mexico, model \#7001021009.

- Body mass index:, Calculated by dividing the weight of a person $(\mathrm{kg})$ by the square height $(\mathrm{m})$ (Sizer and Whitney, 2008). The formulae universally used in medicine produce a unit of measure of $\mathrm{kg} / \mathrm{m}^{2}$.

A frequent use of the BMI is to assess how much an individual's body weight departs from what is normal or desirable for a person of his or her height .The weight excess or deficiency may, in part, be accounted for by body fat (adipose tissue) although other factors such as muscularity also affect BMI significantly. 
WHO (2006) categorized BMI as:

Table 1. Categories of Body Mass Index

\begin{tabular}{ll}
\hline Category & BMI range $\mathbf{~ k g / \mathbf { m } 2}$ \\
\hline Underweight & $<18.5$ \\
Normal (healthy weight) & $18.5-24.9$ \\
Overweight & $25-29.9$ \\
Obese Class I (Moderately obese) & $30-34.9$ \\
Obese Class II (Severely obese) & $35-40$ \\
Obese Class III (Very severely obese) & $>40$ \\
\hline
\end{tabular}

\subsubsection{Biochemical Assessment}

Blood sugar level was measured by using HbA1c instrument (Labona Check ${ }^{\mathrm{TM}} \mathrm{A} 1 \mathrm{C}$ HbAlc test kit made in Korea). The results were taken after three months.

\subsection{Dietary Intakes}

The method of 24 hour-recall was used to collect data about dietary intake of diabetes.

\subsection{Data Analysis}

Data was analyzed by using Software Package of Social Sciences, SPSS version (20) the following features of SPSS were used:

- Calculation of frequency and percentage.

- Chi Squire Test to determine the correlation between variables.

- Paired Samples T- Test to know the differences in BMI and HbAlc among the respondents before and after intake of Arabic Gum.

\section{Results}

Result in Table 2. Showed the classification of diabetes (Type II) according to sex \& age. Females to males represented by $(60 \%)$ and $(40 \%)$ of patients respectively. (64\%) of them age above 50 years.

Table 2. Classification of Diabetes (Type II) According to Sex and Age Groups

\begin{tabular}{|c|c|c|c|c|c|c|}
\hline \multirow{3}{*}{ Age (years) } & \multicolumn{4}{|c|}{ Sex } & \multicolumn{2}{|c|}{ Total } \\
\hline & \multicolumn{2}{|c|}{ Males } & \multicolumn{2}{|c|}{ Females } & \multirow{2}{*}{ No. } & \multirow{2}{*}{$(\%)$} \\
\hline & No. & $(\%)$ & No. & $(\%)$ & & \\
\hline$(30-40)$ & 0 & 0.0 & 1 & 6.7 & 1 & 4.0 \\
\hline$(41-50)$ & 3 & 30.0 & 5 & 33.3 & 8 & 32.0 \\
\hline Above 50 & 7 & 70.0 & 9 & 60.0 & 16 & 64.0 \\
\hline Total & 10 & 100.0 & 15 & 100.0 & 25 & 100.0 \\
\hline Chi squire value & & 0.78 & $\mathrm{P}$ va & & $0.7 *$ & \\
\hline
\end{tabular}

* No significant difference between males and females in age.

Table 3 showed that (36\%) of patients have high school education. while university, primary, and illiterate level represented by $(28 \%),(32 \%)$, and (4\%) of patients respectively. 
Table 3. Classification of Diabetes (Type II) and Educational Level

\begin{tabular}{|c|c|c|c|c|c|c|}
\hline \multirow[b]{3}{*}{ Level of Education } & \multicolumn{4}{|c|}{ Sex } & \multicolumn{2}{|l|}{ Total } \\
\hline & \multicolumn{2}{|c|}{ Male } & \multicolumn{2}{|c|}{ Female } & \multirow[b]{2}{*}{ No. } & \multirow[b]{2}{*}{$(\%)$} \\
\hline & No. & $(\%)$ & No. & $(\%)$ & & \\
\hline Illiterate & 0 & 0.0 & 1 & 6.7 & 1 & 4.0 \\
\hline Primary School & 3 & 30.0 & 5 & 33.3 & 8 & 32.0 \\
\hline High School & 1 & 10.0 & 8 & 53.3 & 9 & 36.0 \\
\hline University Education & 6 & 60 & 1 & 6.7 & 7 & 28.0 \\
\hline Total & 10 & 100.0 & 15 & 100.0 & 25 & 100.0 \\
\hline Chi squire value & & 11.4 & & & $P$ value & $0.02 *$ \\
\hline
\end{tabular}

* There is significant difference between males and females in education.

Table 4 showed that (68\%) of the study group were unemployed, (12\%) were governmental employed, and (20\%) were self-employed.

Table 4. Classification of Diabetes (Type II) According to Occupation

\begin{tabular}{|c|c|c|c|c|c|c|}
\hline \multirow{3}{*}{ Occupation } & \multicolumn{4}{|c|}{ Sex } & \multicolumn{2}{|l|}{ Total } \\
\hline & \multicolumn{2}{|c|}{ Males } & \multicolumn{2}{|c|}{ Females } & \multirow{2}{*}{ No. } & \multirow{2}{*}{$(\%)$} \\
\hline & No. & $(\%)$ & No. & $(\%)$ & & \\
\hline Unemployed & 5 & 50.0 & 12 & 80.0 & 17 & 68.0 \\
\hline Government employed & 3 & 30.0 & 0 & 0.0 & 3 & 12.0 \\
\hline Self-employed & 2 & 20 & 3 & 20 & 5 & 20 \\
\hline Total & 10 & 100.0 & 15 & 100.0 & 25 & 100.0 \\
\hline Chi Squire value & & 5.4 & & & $P$ value & $0.1 *$ \\
\hline
\end{tabular}

* No significant difference between males and females in occupation.

Table 5.Indicated that (44\%) of the patients have middle income, $(36 \%)$ and $((20 \%)$ of them have high, and low income respectively.

Table 5. Classification of Diabetes (Type II) According to Income Levels

\begin{tabular}{|c|c|c|c|c|c|c|}
\hline \multirow{3}{*}{ Levels of Income/month } & \multicolumn{4}{|c|}{ Sex } & \multicolumn{2}{|l|}{ Total } \\
\hline & \multicolumn{2}{|l|}{ Males } & \multicolumn{2}{|l|}{ Females } & \multirow{2}{*}{ Number } & \multirow{2}{*}{$(\%)$} \\
\hline & Number & $(\%)$ & Number & $(\%)$ & & \\
\hline Low & 2 & 20.0 & 3 & 20.0 & 5 & 20.0 \\
\hline Middle & 5 & 50.0 & 6 & 40.0 & 11 & 44.0 \\
\hline High & 3 & 30.0 & 6 & 40.0 & 9 & 36.0 \\
\hline Total & 10 & 100.0 & 15 & 100.0 & 25 & 100.0 \\
\hline Chi squire value & & & .1 & & value & $0.8^{*}$ \\
\hline
\end{tabular}

* No significant difference between males and females in their income. 
Results with patients follow up indicated some of them suffered from side effects of Gum Arabic, represented by $(26.6 \%)$ of them suffered from nausea, while $(6.1 \%)$ of the patients suffer from chronic diarrhea and the same percentage of them suffer from constipation. So that not all patients were fully committed to Gum Arabic consumption.

Table 6 showed pared t-test for patients BMI before and after Gum Arabic consumption for type II diabetes .The mean of BMI of the respondents before consumption of Gum Arabic was (29.8 \pm 2.4 ) compared to (29.6 \pm 5.9$)$ after consumption of Gum Arabic with mean difference (0.2). T-value was 0.31 which is not significant at probability value $(\mathrm{P}=0.7)$.

The mean of $\mathrm{HbA}_{1 \mathrm{c}}$ of the respondents before consumption of Gum Arabic was (7.5 \pm 1.3 ) compared to (7.7 \pm 1.8 ) after consumption of Gum Arabic with mean difference (-0.2). T-value was -0.95.

Table 6. Pared T-test of BMI \& HbA1c for type II Diabetes Before and After Gum Arabic Consumption

\begin{tabular}{|c|c|c|c|c|c|c|c|}
\hline Variables & Groups & Mean & $\pm \mathrm{SD}$ & Mean difference & $\mathrm{T}$ value & $\mathrm{DF}$ & $P$ value \\
\hline \multirow[b]{2}{*}{ BMI } & Before & 29.8 & 2.4 & \multirow[b]{2}{*}{0.2} & \multirow{2}{*}{0.31} & \multirow[b]{2}{*}{24} & \multirow{2}{*}{$0.7^{*}$} \\
\hline & After & 29.6 & 5.9 & & & & \\
\hline \multirow{2}{*}{ HbAlc (\%) } & Before & 7.5 & 1.3 & \multirow{2}{*}{-0.2} & \multirow{2}{*}{-0.95} & \multirow{2}{*}{24} & \multirow{2}{*}{$0.5^{*}$} \\
\hline & After & 7.7 & 1.8 & & & & \\
\hline
\end{tabular}

* No significant difference between values before and after Gum Arabic consumption.

Table 7 shows the changes in CHO intake among those who fully committed to Gum Arabic consumption. (75\%) of patients increased their carbohydrates intake, while $(25 \%)$ decreased their intake. Significant differences reported between males and females who fully committed to consumption of Gum Arab.

Table 7. Change in CHO Intake among Diabetes who fully committed to Gum Arabic Consumption

\begin{tabular}{|c|c|c|c|c|c|c|}
\hline \multirow{3}{*}{ Change in Dietary Habits } & \multicolumn{4}{|c|}{ Gender } & \multicolumn{2}{|l|}{ Total } \\
\hline & \multicolumn{2}{|l|}{ Males } & \multicolumn{2}{|l|}{ Females } & \multirow{2}{*}{ Number } & \multirow{2}{*}{$(\%)$} \\
\hline & Number & $(\%)$ & Number & $(\%)$ & & \\
\hline Patients who increase their $\mathrm{CHO}$ intake & 2 & 50.0 & 4 & 100.0 & 6 & 75.0 \\
\hline Patients who decrease their $\mathrm{CHO}$ intake & 2 & 50.0 & 0 & 0.0 & 2 & 25.0 \\
\hline Total & 4 & 100.0 & 4 & 100.0 & 8 & 100.0 \\
\hline Chi squire & & 12.9 & & & P value & $0.04 *$ \\
\hline
\end{tabular}

*Significant difference between males and females in change of CHO intake.

Table 8 showed Pared Sample T-test the mean BMI and (\%) HbAlc of patients who fully committed to Gum Arabic consumption. The mean BMI of the respondents was (28.9 \pm 4.39$)$ compared to (29.2 \pm 5.73$)$ after consumption of Gum Arabic with mean difference (-0.7). T-value was -0.31 which is not significant at probability value $(\mathrm{P}=0.7)$. HbA1c was $(7.3 \%)$ before and after Gum Arabic consumption.

Table 8. Pared T-test of BMI among Fully Committed Diabetes to Gum Arabic Consumption

\begin{tabular}{|c|c|c|c|c|c|c|c|}
\hline Variables & Groups & Mean & $\pm \mathrm{SD}$ & Mean difference & $\mathrm{T}$ value & DF & $P$ value \\
\hline \multirow{2}{*}{ BMI } & Before & 28.9 & 4.39 & \multirow{2}{*}{-0.7} & \multirow{2}{*}{-0.31} & \multirow{2}{*}{7} & \multirow{2}{*}{$0.7 *$} \\
\hline & After & 29.2 & 5.73 & & & & \\
\hline HbA1c & Before & 7.3 & 1.65 & \multirow{2}{*}{0.01} & \multirow{2}{*}{0.02} & \multirow{2}{*}{7} & \multirow{2}{*}{$0.9^{*}$} \\
\hline$(\%)$ & After & 7.3 & 1.94 & & & & \\
\hline
\end{tabular}

* No significant difference in HbA1c means values before and after Arabic Gum consumption. 


\section{Discussion}

Classification of diabetes Type II according to sex and age. Most of patients were female that means type II diabetes mellitus effect females more than males. Also it was common among those who were above 50 years old.

More than half of patients have high school and university education levels. That's means majority of the respondents were educated.

Most of the study group were unemployed, that's means type II diabetes mellitus causes low productivity. A bout half of the patients have middle income, and few of them have low income.

Many of the patients were not fully committed to the Gum Arabic consumption because the experienced side effects including possible allergies in some patients towards Arabic gum. This agrees with result of Babiker et al. (2012) and Vinik \& Jenkins (1988). They reported that Arabic gum caused gastrointestinal side effects for some of the respondents.

The mean BMI before and after Gum Arabic consumption for type II diabetes in the two periods indicated that it was slightly higher before than after consumption of Gum Arabic but there was no significant difference. Similar result was obtained by Ahmed (2007) who found that weight gain was significantly depressed for rabbits that consumed Gum Arabic in the first week of the experiment but effect on weight gain was recovered thereafter. This result is in contrast with results of Ushida (2011) and Babiker et al. (2012). The former done a research in Gum Arabic and its anti-obesity effect; on the other hand, the latter concluded that ingestion of Gum Arabic caused significant reduction in body mass index on adult females.

The percentage mean $\mathrm{Hb} \mathrm{A}_{1 \mathrm{C}}$ of the study group before the consumption of Gum Arabic was slightly less than after consumption; however there were no significant differences in the two periods. The two means fall within more than (7\%). As all diabetes should maintain their $\mathrm{HbA}_{1 \mathrm{c}}$ level below (7\%) as recommended by Davidson, (1998). This result similar to results by (Wadood et al., 1989) who stated that Gum Arabic did not produce Signiant hypoglycemic effect in diabetic rabbits. In contrast to the results of (Post, 2012 et al., 2011) who found that dietary fibers can both reduce fasting blood glucose and improve glycosylated hemoglobin $\left(\mathrm{Hb} \mathrm{A}_{1 \mathrm{C}}\right)$ in type II diabetes mellitus patients.

Among those who fully committed to Gum Arabic consumption, there was change in their carbohydrates intake. Significant differences were reported between males and females $(p<0.04)$. All females increased their carbohydrates intake .Similar result obtained by Burger et al., (2012) and Salmeron et al., (1997). The former found that the patients increased the carbohydrate intake, and the latter found that diets with a high glycemic load and a low cereal fiber content increase risk of type II diabetes diabetes. This result in contrast with results of Ushida (2011) who showed that diets of the respondents at the end of the study had lower caloric density than at the beginning.

Although males reported more reduction in BMI than females after consumption of Gum Arabic with full commitment to consumption, no significant differences in BMI in the two periods. Similar result obtained by Ahmed (2007). This results is in contrast to results of (Ushida, 2011; Babiker et al., 2012). The mean percentage of $\mathrm{HbA}_{1 \mathrm{c}}$ before the consumption of Gum Arabic was slightly less than after consumption; however, the two means fall within greater than $(7 \%)$.

This result similar to results by (Ross et al., 1983; Ahmed, 2007; Eunice \& Gerard, 2013). In contrast to the results of (Chandalia et al., 2000; Ebeling et al., 1988; Mclntosh \& Miller, 2001; Tabatabai \& Li, 2000; Riccardi \& Rivellese, 1991; \& Khatun et al., 2011) who stated that food rich in soluble and insoluble fiber can improve glycemic control among patients with type II diabetes.

\section{Conclusions and Recommendations}

The results of this study didn't confirm the hypothesis, where we found that Arabic gum did not reduce blood glucose level and body mass index for type II diabetes. So that further study should be conducted to another group of patients and to be more committed with their Arabic Gum consumption.

As this study was conducted in the winter the researcher found that the majority of the respondents increased their carbohydrate intake, which might be a reason why there were no reduction in the $\mathrm{BMI}$ and $\mathrm{HbA}_{1 \mathrm{c}}$ of the patients, so that further study should be conducted in the summer to compare it with this study to know the effect of seasons on dietary patterns of type II diabetes. Also researchers should encourage type II diabetes to abide full commitment to Arabic Gum consumption and not to change their dietary systems. 


\section{Acknowledgements}

A special gratitude is given to College of Nursing Sciences lab and lab of Jabir Abu Aliz Diabetic Center, who gave the permission to use all required equipment's and the necessary materials to complete the task. Thanks are extended to Elanan Trading Exports and Imports Company Ltd., Khartoum, Sudan, for providing Gum Arabic with discounting price and to Mr. Shwagi for the finical support.

Furthermore, the authors would like to acknowledge with much appreciation the crucial role of the staff of Therapeutic Nutrition Department at University of Khartoum whose contribution in stimulating suggestions and encouragement.

\section{Competing Interests Statement}

The authors declare that they has no competing or potential conflicts of interest.

\section{References}

Ahmed, S. (2007). Response of Rabbits to Dietary Gum Arabic, Sudan. Retrieved 21 Dec, 2012 from http://hdl.handle.net/123456789/8240

Alsuleimani, Y, Alzabi, M., Ramkumar, A., Almhruqui, M., TAgeldin, A., Nemar, A. et al. (2015). Influence of treatment with Gum Acacia on renal vascular responses in a rat model of chronic kidney disease. J. Eur. Rev. Med Pharmacol. Sci., 19(3), 494-506.

Anonymous. (2008). The power of fiber. Retireved Oct, 2015, from www.everydayhealth.com

Babiker, R., Merghani, T. H., Elmusharaf, K., Badi, R. M., Lang, F., \& Saeed, A. M. (2012). Effects of Gum Arabic ingestion on body mass index and body fat percentage in healthy adult females: two-arm randomized, placebo controlled, double-blind trial. Nutrition journal, 11(1), 111. https://doi.org/10.1186/1475-2891-11-111

Bays, H. E., Chapman, R. H., \& Grandy, S. (2007). The relationship of body mass index to diabetes mellitus, hypertension and dyslipidaemia: comparison of data from two national surveys. International journal of clinical practice, 61(5), 737-747. PMID: 17493087. Retrieved from http;//www.ncbi.nlm.nih.gov

Burger, K. N., Beulens, J. W., van der Schouw, Y. T., Sluijs, I., Spijkerman, A. M., Sluik, D., ... \& Overvad, K. (2012). Dietary fiber, carbohydrate quality and quantity, and mortality risk of individuals with diabetes mellitus. PLoS One, 7(8), e43127.

Chandalia, M., Garg, A., Lutjohann, D., von Bergmann, K., Grundy, S. M., \& Brinkley, L. J. (2000). Beneficial effects of high dietary fiber intake in patients with type 2 diabetes mellitus. New England Journal of Medicine, 342(19), 1392-1398.

Chiavaroli, L., Mirrahimi, A., Sievenpiper, J. L., Jenkins, D. J. A., \& Darling, P. B. (2015). Dietary fiber effects in chronic kidney disease: a systematic review and meta-analysis of controlled feeding trials. European journal of clinical nutrition, 69(7), 761-768.

Davidson, B. (1998). Diabetes Mellitus: Diagnosis and Treatment (4th ed.). USA, W.B.Saunders Company.

Ebeling, P., Yki-Järvinen, H., Aro, A., Helve, E., Sinisalo, M., \& Koivisto, V. A. (1988). Glucose and lipid metabolism and insulin sensitivity in type 1 diabetes: the effect of guar gum. The American journal of clinical nutrition, 48(1), 98-103.

Egbunike, V., \& Gerard, S. (2013). The impact of point-of-care A1c testing on provider compliance and A1c levels in a primary setting. The Diabetes Educator, 39(1), 66-73. PMID: 23150529.

Eliadarous, H. (2007). Economic burden of diabetes on patients and their families in Sudan. Stockholm, Sweden, Karolinska Institutet.

Glover, D. A., Ushida, K., Phillips, A. O., \& Riley, S. G. (2009). Acacia (sen) SUPERGUM ${ }^{\mathrm{TM}}$ (Gum Arabic): an evaluation of potential health benefits in human subjects. Food Hydrocolloids, 23(8), 2410-2415.

Haslett, C., Chilvers, E., Boon, N., \& Clledge, N. (eds.) (2002). Davidson's Principles and Practice of Medicine (19th ed.). USA, Churchill Livingstone.

Karg, C., Alfred, L., \& Gmb, H. (2000). The Nutritional Benefits of Gum Arabic (acacia gum). Germany, Gr. archerstr. Available from: Nutraceuticals Now [Accessed Jan 2013].

Khatun, H., Rahman, A., Biswas, M., \& Islam, A. (2011). Water-soluble Fraction of Abelmoschusesculentus L Interacts with Glucose and Metformin Hydrochloride and Alters Their Absorption Kinetics after co-administration in Rats. PMID: 22389848. Retrieved from http;//www.ncbi.nlm.nih.gov. 
Kumar, P., \& Clark, M. (Eds.). (1998). Clinical Medicine (4th ed.). UK, W. B. Saunders.

Mcintosh, M., \& Miller, C. (2001). A diet containing food rich in soluble and insoluble fiber improves glycemic control and reduces hyperlipidemia among patients with type 2 diabetes mellitus. Nutrition Reviews, 59(2), 52-55. PMID: 11310776. https://doi.org/10.1111/j.1753-4887.2001.tb06976.x

Mohamed, R. E., Gadour, M. O., \& Adam, I. (2015). The lowering effect of Gum Arabic on hyperlipidemia in Sudanese patients. Frontiers in physiology, 6. PMID: 26042049. https://doi.org/10.3389/fphys.2015.00160

Nasir, O., Artunc, F., Saeed, A., Kambal, M. A., Kalbacher, H., Sandulache, D., ... \& Lang, F. (2008). Effects of gum arabic (Acacia senegal) on water and electrolyte balance in healthy mice. Journal of Renal Nutrition, 18(2), 230-238. PMID: 18267216. https://doi.org/10.1053/j.jrn.2007.08.004

Nasir, O., Umbach, A. T., Rexhepaj, R., Ackermann, T. F., Bhandaru, M., Ebrahim, A., ... \& Föller, M. (2012). Effects of gum arabic (Acacia senegal) on renal function in diabetic mice. Kidney and Blood Pressure Research, 35(5), 365-372. PMID: 18267216. https://doi.org/10.1159/000336359

Osman, M., Abu Zeid, I., \& Adam, F. (2011). Health benefits of Gum Arabic. In J. F., Kennedy, G. O., Phillips, and P. A., Williams, (Eds.), Gum Arabic. UK. The Royal Society of Chemistry.

Riccardi, G., \& Rivellese, A. A. (1991). Effects of dietary fiber and carbohydrate on glucose and lipoprotein metabolism in diabetic patients. Diabetes care, 14(12), 1115-1125.

Ross, A. H., Eastwood, M. A., Brydon, W. G., Anderson, J. R., \& Anderson, D. M. (1983). A study of the effects of dietary gum arabic in humans. The American journal of clinical nutrition, 37(3), 368-375.

Salmeron, J., Manson, J. E., Stampfer, M. J., Colditz, G. A., Wing, A. L., \& Willett, W. C. (1997). Dietary fiber, glycemic load, and risk of non - insulin-dependent diabetes mellitus in women. Jama, 277(6), 472-477.

Sizer, F., \& Whitney, E. (2008). Nutrition: Concepts and Controversies. USA: Cengage Learning.

Tabatabai, A., \& Li, S. (2000). Dietary fiber and type II, USA. Clin Excell Nurse Pract, 4(5), 272-6. PMID: 11858448. Retrieved from http://www.ncbi.nlm.nih.gov

Ushida, K. (2011). Health benefits. In J., Kennedy, G., Phillips, \& P., Williams, (Eds)., Gum Arabic. UK. The Royal Society of Chemistry.

Wadood, A. B. D. U. L., Wadood, N. O. R. E. E. N., \& Shah, S. A. (1989). Effects of Acacia arabica and Caralluma edulis on blood glucose levels of normal and alloxan diabetic rabbits. JPMA. The Journal of the Pakistan Medical Association, 39(8), 208-212. PMID: 2509753.

Wadood, N., Wadood, A., \& Shah, S. A. W. (1992). Effect of Tinospora cordifolia on blood glucose and total lipid levels of normal and alloxan-diabetic rabbits. Planta Medica, 58(02), 131-136. https://doi.org/10.1055/s-2006-961414

World Health Organization. (2006). Database on Body Mass Index. Retrieved from https://www.nice.org.uk

\section{Copyrights}

Copyright for this article is retained by the author(s), with first publication rights granted to the journal.

This is an open-access article distributed under the terms and conditions of the Creative Commons Attribution license (http://creativecommons.org/licenses/by/4.0/). 